\title{
Prediction of the effects of friction control on top-of-rail cracks
}

\author{
Saad Ahmed Khan', Ingemar Persson², Jan Lundberg' \\ and Christer Stenström'
}

(9SAGE

\begin{abstract}
Rolling contact fatigue is a major problem connected with railway tracks, especially in curves, since it leads to higher maintenance costs. By optimising the top-of-rail friction, the wear and cracks on the top of the rail can eventually be reduced without causing very long braking distances. There are several research articles available on crack prediction, but most of the research is focused either on rail without a friction modifier or on wheels with and without friction control. In the present study, in order to predict the formation of surface-initiated rolling contact fatigue, a range of friction coefficients with different Kalker's reduction factors has been assumed. Kalker's reduction factor takes care of the basic tendency of creepage as a function of the traction forces at lower creepage. The assumed range covers possible friction values from those for non-lubricated rail to those for rail with a minimum measured friction control on the top of the rail using a friction modifier. A fatigue index model based on the shakedown theory was used to predict the generation of surface-initiated rolling contact fatigue. Simulations were performed using multi-body simulation, for which inputs were taken from the Iron Ore line in the north of Sweden. The effect of friction control was studied for different curve radii, ranging from $200 \mathrm{~m}$ to $3000 \mathrm{~m}$, and for different axle loads from 30 to 40 tonnes at a constant train speed of $60 \mathrm{~km} / \mathrm{h}$. One example of a result is that a maximum friction coefficient $(\mu)$ of 0.2 with a Kalker's reduction factor of $15 \%$ is needed in the case of trains with a heavy axle load to avoid crack formation.
\end{abstract}

\section{Keywords}

Rolling contact fatigue, fatigue index, friction modifier, friction control, rail

Date received: 2 June 2016; accepted: 25 September 2016

\section{Introduction}

For longer distances and heavy loads, the railway system is still the most economical means of transportation. Because of increasing competition, railway operators are continuously working to improve the overall operational efficiency. ${ }^{1,2}$ In order to achieve higher operational efficiency, the axle load needs to be increased. An increased axle load increases the traction forces between the rail and wheel, which in turn increase the wear and the rolling contact fatigue (RCF) and, consequently, increases the maintenance cost of the infrastructure. As reported by Trafikverket (the infrastructure manager in Sweden), the lifetime of the rail is limited, especially in the case of heavy haul lines, mainly due to RCF on the top of the rail, which basically causes surface-initiated cracks. The traction forces are even more severe in small-radius (sharp) curves, which make such curves more prone to damage. Ignorance of cracks due to RCF at their initial stage can lead to a catastrophic accident, as cracks propagate fast once they have been generated. Wear is also considered as a damaging effect, but generally it is not as catastrophic as cracks and sometimes artificial wear (grinding) is carried out to remove surface cracks. However, grinding is expensive in terms of both resources and track access time, and there is therefore always a need to increase the time interval for grinding. To increase the lifetime of the rails without compromising on the axle load and speed, one must either increase the strength of the rails or decrease the traction forces between the rails and wheels.

Unlike road vehicles (e.g. cars and buses), trains do not have steering mechanisms. Practically, a train is steered partially with the help of the rolling radius difference between the high and low wheel of the same axle, and partially with the help of the wheel flange. Ideally, the rolling radius difference between

\footnotetext{
'Division of Operation and Maintenance, Luleå University of Technology, Sweden

${ }^{2} A B$ DEsolver, Östersund, Sweden

\section{Corresponding author:}

Saad Ahmed Khan, Division of Operation and Maintenance, Luleå University of Technology, Luleå SE-97I87, Sweden.

Email: saad.ahmed.khan@Itu.se
} 
the high and low wheels should be enough to negotiate the curve, but practically this is not the case, as a result of which the outer wheel flange hits the rail to negotiate the curve. When the flange hits the rail, this results in a wheel contact consisting of two point contacts (valid for the special wheel and rail profiles of heavy haul trains); one point is located between the wheel tread and the top of the rail and the other point between the wheel flange and rail gauge. ${ }^{3}$ In some special cases, the wheel and rail can have more than two contact points due to facets created by grinding, but those cases are not covered in this study. The motion between the wheel tread and the top of the rail is a rolling motion (not an ideal rolling), which makes the train run, whereas the motion between the wheel flange and rail gauge (especially in the case of heavy haul trains) is generally a pure sliding motion, which helps in steering and keeps the axle in a confined position to avoid derailment. The flange sliding behaviour is dependent on the rail-wheel profile and for some profiles it may not consist of a pure sliding motion. The degree of flange sliding depends on the rail-wheel profile, the curvature of the track and the stiffness of the primary suspension.

The shakedown diagram was developed by Bower and Johnsson ${ }^{4}$ who used it in a study on the modelling of near-surface plastic deformation caused by repeated wheel-rail contact and reported that, by reducing the utilised friction coefficient between the rail and wheel and thus minimising the traction forces, the probability of RCF formation could be controlled. The friction between the wheel flange and rail gauge should be as low as possible (which is not focused in this paper), if the wheel-rail profiles are designed to have a pure sliding motion. However, excessively reduced friction between the rail head and wheel tread can cause slippage and/or too long a braking distance. Therefore, the utilised friction between the wheel tread and the top of the rail (rail running surface) needs to be controlled and kept within a particular range of friction coefficients. This friction coefficient range provides the minimum possible traction forces without wheel slippage or a long braking distance. The top-of-rail friction modifier, whose use was first reported in 2003 by Eadie et al., ${ }^{5}$ has emerged as a possible solution to traction force control. Top-of-rail friction modifier (TOR-FM) is a product which, according to the claims of the manufacturers, controls the friction coefficient and keeps it in a certain range between the rail head and wheel tread. TOR-FM has been tested and even implemented at several North American heavy haul railway sites. ${ }^{6}$ It has also been studied in combination with gauge face lubrication (which is also known as friction management) in China $^{7}$ and Australia. ${ }^{8}$ In addition, many laboratory tests have been performed using a twin-disc test rig 9 and a full-scale rail-wheel test rig, ${ }^{10}$ and a reduction in both wear and cracks has been reported.
Sweden's Iron Ore Line (IOL), situated in the north of the country, is mainly used for transporting iron ore from the mines in Kiruna and Malmberget to the seaports of Luleå in Sweden and Narvik in Norway. Till date, no TOR friction control has been implemented on this line and cracks are a major problem on the line, especially in curves. Before starting a field test, the performance of simulations is recommended, as they are cheaper and faster than field tests. ${ }^{3}$ Simulation models with correct inputs can predict the effect of friction control on wheel-rail damage and can be used to understand the effect of friction on rail damage. Another advantage of such prediction models is their ability to analyse the life cycle cost of using a friction controller in the wheel-rail interface. Ekberg et al. ${ }^{11}$ developed a fatigue index (FI) model based on the shakedown diagram to predict the generation of surface-initiated RCF on railway wheels. This model has been verified and validated by researchers in the past few years. ${ }^{12}$

The present study is part of a project called the Top of the Rail (TOR) Project, which is supported by the railway infrastructure manager in Sweden, Trafikverket. The project includes both field tests and computer-based simulations. The results from this study will be compared with the results from future field tests performed for validation purposes. After successful validation, it will be possible to use the results of simulations to calculate the economic efficiency of the TOR system.

\section{Methods}

In the present study, simulations were performed using measurement data (obtained using track inspection trains and a handheld laser device) from in-service wheels and rail on the IOL. The reason for using profiles of in-service (used) wheels and rail was that they generally generate different contact forces (ranging from higher to lower) due to asperities and surface deformation. ${ }^{13}$ For performing simulations, a range of friction coefficients with different Kalker's reduction factors was used. Kalker's reduction factor takes care of the basic tendency of creepage as a function of the traction force at lower creepage. ${ }^{14}$ The assumed friction control values (including both the friction coefficient and the Kalker's reduction factor), along with the measured rail-wheel profiles and track irregularities, were input into a multi-body simulation (MBS) from the GENSYS ${ }^{15}$ software. In 2015, the wheel and rail profiles were measured using a Calipiri 40 device from Nextsense, and the track irregularities (the longitudinal level, line, cant and gauge irregularities) were measured by a special track recording train (IMV100). The MBS performed the wheel-rail contact mechanics modelling, which is based on Hertzian theory in combination with Kalker's simplified theory of rolling contact (the FASTSIM algorithm). ${ }^{16}$ 


\section{Friction values}

Traditionally, the friction coefficient between surfaces is measured using a pin-on-disc, twin-disc ${ }^{17}$ or fullscale test rig $^{13}$ in laboratories. However, in small laboratory tests, one encounters a scaling factor problem and the problem of achieving realistic surface roughness and ambient conditions, e.g. snow, humidity, deposits from brakes, dust from ore and the environment, etc. Big-rig tests overcome the scale factor, but real field conditions and surface roughness are still not feasible. To achieve realistic environmental conditions, a handheld tribometer can be used, but with such a tribometer there is a lower contact pressure between the contact surfaces than there is in real wheel-rail contact. This lower contact pressure leads to unrealistic estimations of the friction between the rail and wheel. ${ }^{18}$ One of the most reliable ways to obtain realistic values for the friction between the rail and wheel is to use a friction measurement device installed on board a locomotive, ${ }^{18}$ although this method is impractical owing to its high cost. The on-board device measures the friction under natural environmental conditions, uncontrolled by humans. The values measured using the on-board friction measurement device and the values calculated from laboratory tests contradict each other, which could be due to differing ambient conditions. In the case of the on-board device, the ambient conditions (e.g. the surface roughness, temperature, humidity, third body, etc.) are considered, but they can vary dramatically. Therefore, a range of intermediate friction coefficient values was used for the simulations in the present study (see Figure 1). The future solution regarding friction measurement could be an improved

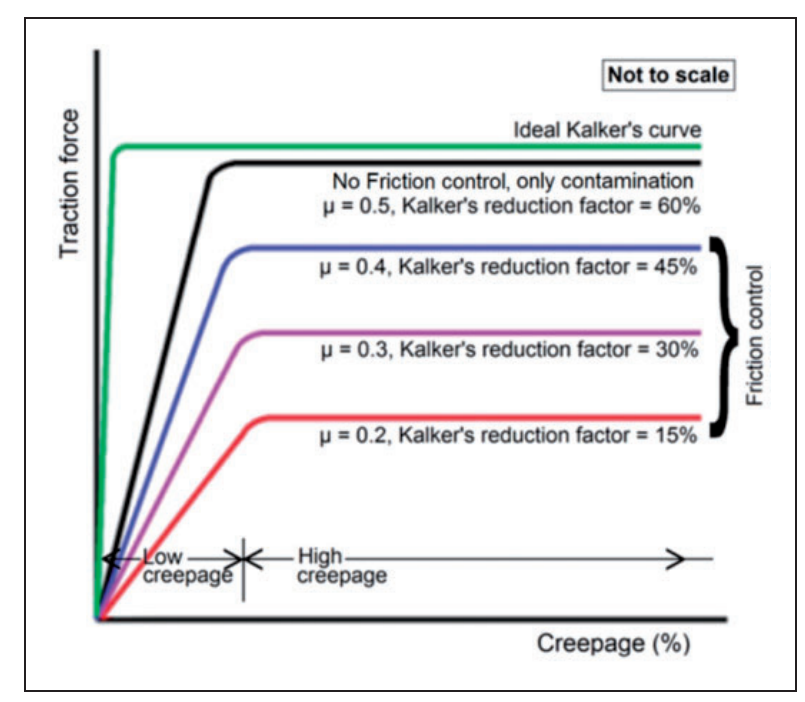

Figure I. Traction force-creepage diagram, showing the trend with different levels of friction control (combinations of friction coefficient and Kalker's reduction factor) with respect to the traction force. The horizontal line indicates full slip and the slanting line indicates partial slip. Adapted from VanderMarel et al. ${ }^{14}$ handheld device for use in the field. The cost of the equipment should be low and the contact pressure should be the same as that of the wheel-rail contact.

Another important factor that needs to be considered is that the friction between the rail and wheel rarely involves full slip and often involves partial slip. Measurements made by Johnson ${ }^{19}$ showed that Kalker's theory applies to ideal wheels and rails. According to this theory, which focuses on the ideal condition, the partial slip condition (the topmost slanting line in Figure 1) occurs when there are very small creepage values. If the surfaces are contaminated, the friction coefficient is reduced and a reduction factor has to be introduced; i.e. contamination acts as a lubricant/friction modifier. On the introduction of a reduction factor, partial slip (the second slanting line from the top in Figure 1) occurs when there are comparatively larger creepage values. A friction coefficient of 0.5 and a reduction factor of $60 \%$ in the ideal Kalker's curve were used in the present study to predict the non-lubricated (dry) condition. ${ }^{3}$ The friction modifier decreases not only the friction coefficient but also the slope of the partial friction approximately four times (a reduction factor of 15\% of ideal Kalker's curve). ${ }^{14}$ In other words, at any given value of creepage, the friction modifier gives much lower traction forces. The Kalker's reduction factor used for each individual friction coefficient is shown in Figure 1.

For the Kalker's reduction factors of $60 \%$ for $\mu=0.5$ and $15 \%$ for $\mu=0.2$, reduction factors were derived from the results of VanderMarel et al. ${ }^{14}$ and they represent the highest and the lowest limit. The reduction factors for $\mu=0.4$ and $\mu=0.3$ are assumed values selected between the highest and the lowest values. Using these combinations of a friction coefficient and a reduction factor, the simulations performed imitated the presence of the friction modifier on the top of the rail.

Friction modifiers are generally water-based lubricants, which can be applied directly on the top of the rail, forming a micron-scale friction modifier film after drying. ${ }^{17}$ It is claimed by the manufacturers that these films control the friction coefficient and keep it in a particular range, depending on the amount of friction modifier applied and the chemical composition of the modifier. For the present simulations, a fixed value of Kalker's reduction factor was chosen for each individual friction coefficient and for the complete railway curve. The values used in the present study are based on laboratory tests, and no relation was specified between the amount of lubrication and/or base solvent used on the real tracks and the friction control values used in the simulation.

In practical cases, on reaching the full-slip condition at higher creepage levels, the traction force is not constant with respect to the creepage. In dry conditions (i.e. no lubrication and/or contamination), when the creepage is increased, the traction force decreases 


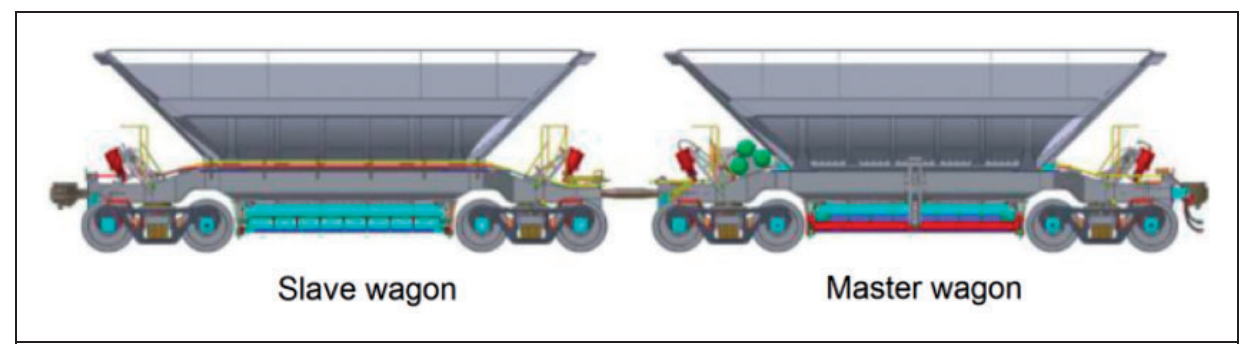

Figure 2. Two-unit iron ore wagon (Fanoo wagon). ${ }^{21}$

slightly, i.e. the saturated friction has a negative slope ${ }^{20}$ which generally leads to stick-slip between the rail and wheel. It is claimed by the manufacturers that, when the friction modifier is used, the traction force never decreases with increasing creepage, i.e. the friction modifier leads to a positive slope at a higher creepage level. For ease of calculation, the zero slope shown in Figure 1 was used for the saturated condition in all cases.

\section{Wagon model and loads}

The multi-body dynamic model of the iron ore wagon, together with the track system, was built using the GENSYS software. ${ }^{15}$ The present iron ore wagons (also known as Fanoo wagons) have four axles with two individual three-piece bogies (Figure 2). The bogies have primary suspension between the axle and side frames and secondary suspension between the side frames and the bolster beam. The primary suspension, which is connected between the axle and side frame, is relatively soft to give the wheel sets good radial self-steering capabilities, so that the wagon can easily negotiate sharp curves. However, this soft suspension system, which is intended to enhance the steering capabilities of the bogie, limits the maximum running speed of the train due to hunting oscillation. $^{3}$ Hunting oscillations are unwanted sinusoidal movements of the axle due to a difference in the rolling radius between the high and low wheel of the same axle. These oscillations cause equilibrium problems after reaching a particular train speed.

Iron ore wagons are connected in pairs: one of the units is called the master wagon and the other is called the slave wagon. The controller of the braking system is attached to the master wagon. The total weight of each wagon for the simulations was taken from a realistic range of 120-160 tonnes (a 30 to 40 tonne axle load) with an increment of 10 tonnes (a 2.5 tonne axle load). At present, an axle load up to 30 tonnes is used and 32.5 tonnes is under testing for Swedish heavy haul trains, but work is in progress to increase the axle load further. The weight distribution of the individual parts, which were considered as rigid bodies, is given in Table 1. For further details of the wagon design, see Nia, ${ }^{21}$ where a similar model was used.
Table I. Weight distribution of the different parts of the wagon.

\begin{tabular}{llc}
\hline Parts & $\begin{array}{l}\text { Number } \\
\text { of units }\end{array}$ & Weight $(\mathrm{kg})$ \\
\hline Car body & $\mathrm{I}$ & 12536 \\
Bolster beam & 2 & 1050 \\
Side frame & 4 & 400 \\
Axle & 4 & 1341 \\
\hline
\end{tabular}

Table 2. Cant (superelevation) used in the field for the respective curve radii and used in the simulation.

\begin{tabular}{ll}
\hline Curve radius $(\mathrm{m})$ & Cant $(\mathrm{m})$ \\
\hline 200 & 0.15 \\
300 & 0.15 \\
400 & 0.1 \\
500 & 0.1 \\
1000 & 0.05 \\
2000 & 0 \\
3000 & 0 \\
\hline
\end{tabular}

\section{Curve data}

For the simulations, the curve radius varied from $200 \mathrm{~m}$ to $3000 \mathrm{~m}$ and the speed of the train for all the curves was fixed to $60 \mathrm{~km} / \mathrm{h}$. This range of radii covers the possible curve radii present in the north of Sweden. The actual cant values designated to the respective curve radii by Trafikverket and used in the simulations are given in Table 2 .

All the simulations were performed for a track length of $700 \mathrm{~m}$, as shown in Figure 3. The circular curve was $250 \mathrm{~m}$ in length and a transition curve of $200 \mathrm{~m}$ was added before and after the circular curve. Before the first transition curve, a $50 \mathrm{~m}$ long tangent track was also included to give a smooth start with lower traction forces. The direction of the bend in all the simulations was towards the right. Therefore, the left rail is denoted as the high rail and the right rail as the low rail. 


\section{Wheel and rail profiles}

To obtain realistic results, in-service profiles from the IOL were chosen for the simulations. The exact profile inputs are shown in Figure 4. The WP4 wheel profile is the base profile and is used for both the high and the low wheels on the axle, whereas the rail has the 60E1 base profile. The base profile of the rails is valid only for new profiles, because, after the first grinding, the profile of the high rail is changed to the MB1, while the low rail retains the $60 \mathrm{E} 1$ profile. The profiles used in the simulation were measured approximately 6 months after grinding was executed. Both the high and the low rails have an inclination of $1 / 30$, which is also reflected in Figure 4. The properties of the 350LHT rail material were used, as that same material is used on the IOL. For further details of the steel, see Voestalpine. $^{22}$

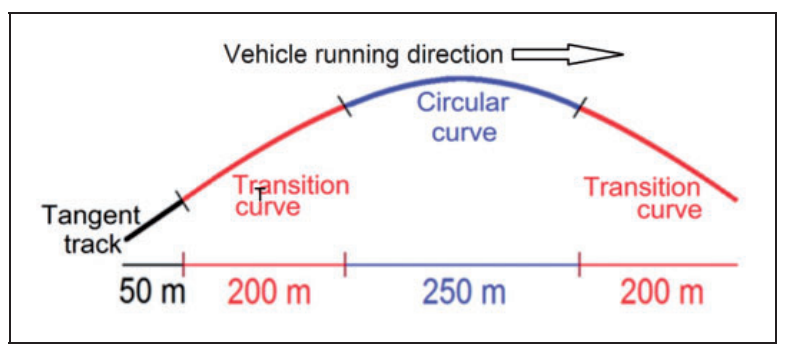

Figure 3. Schematic diagram showing the different zones of the $700 \mathrm{~m}$ curve (with a $50 \mathrm{~m}$ long tangent track) used in the simulation.

\section{RCF prediction model}

The possible forces were generated using multi-body dynamic simulations of the rail-wheel interaction. The output from the dynamic simulations, which consists of the contact forces, creepage, contact position, the size of the contact area, etc., were put into the RCF prediction model.

To predict the generation of surface-initiated cracks (caused by RCF), the FI method, ${ }^{11}$ which is based on the shakedown theory, ${ }^{4}$ was used. According to the FI model the occurrence of RCF depends on the contact pressure, the creep forces in the contact area and the material yield stress in shear. If the external stresses of the working point (WP) exceed the threshold value, which is known as the shakedown limit, surface cracking will occur due to accumulated plastic strain (see Figure 5).

The location of the threshold value (shakedown limit) in the shakedown diagram is a function of the maximum Hertzian contact pressure $\left(P_{o}\right.$ in $\left.\mathrm{N} / \mathrm{m}^{2}\right)$ divided by the shear strength of the material $(k$ in $\mathrm{N} / \mathrm{m}^{2}$ ) in the $y$-axis, and the utilised friction coefficient $(\mu)$ in the $x$-axis. The shear strength $(k)$ depends on the material of the rail, and the contact pressure mainly depends on the contact area and applied load. The utilised friction coefficient $(\mu)$ depends on the creepage and the third body (e.g. dust, water or friction modifier) between the rail and wheel. The friction coefficient is defined as the quotient of the creep forces tangential to the contact surface $\left(F_{t}\right.$ in $\left.\mathrm{N}\right)$ and the

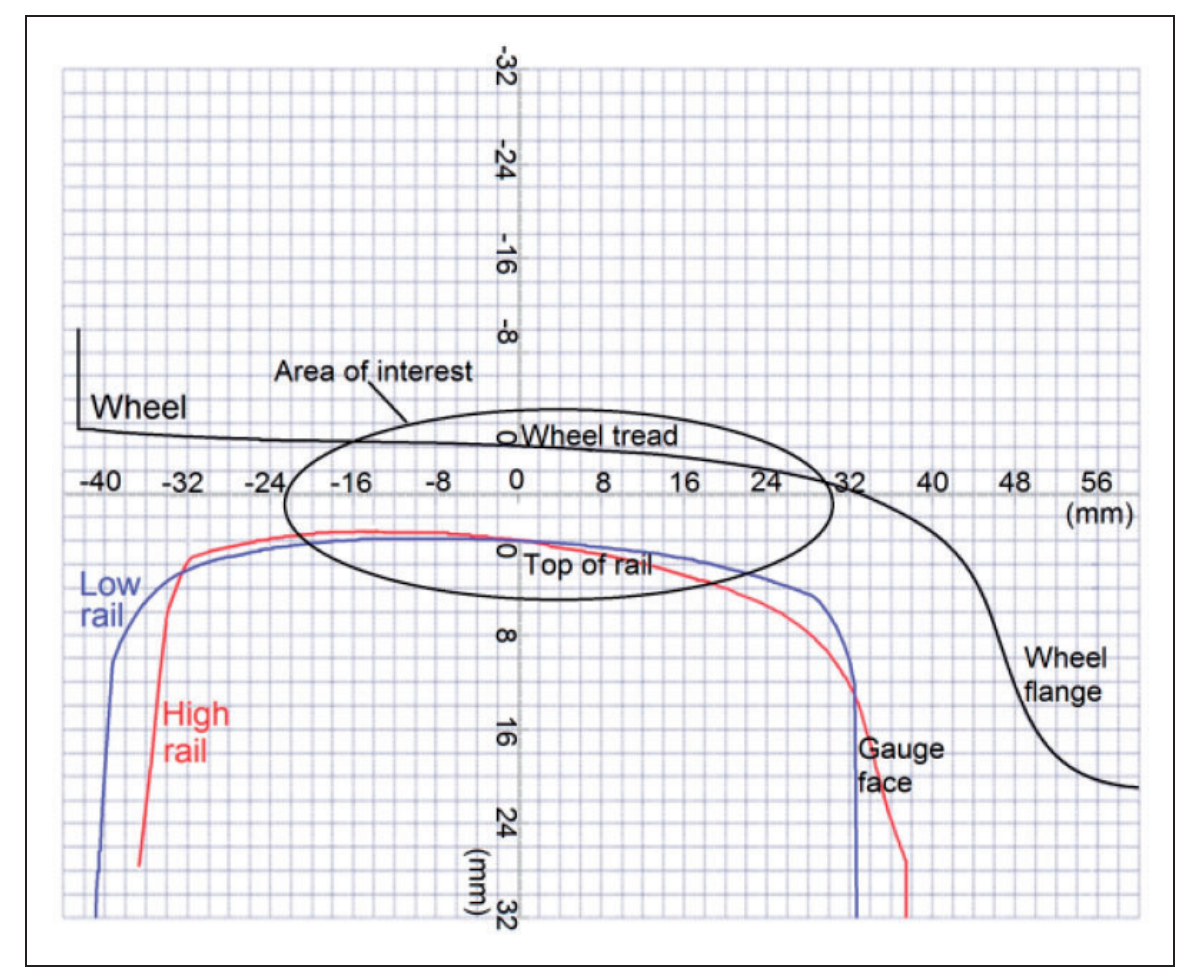

Figure 4. Worn profiles of wheels and rail (both high and low) used in the simulations. 
normal to the contact point $\left(F_{n}\right.$ in $\left.\mathrm{N}\right)$

$$
\mu=\frac{F_{t}}{F_{n}}=\frac{\sqrt{F_{n x}^{2}+F_{n y}^{2}}}{F_{n}}
$$

where $F_{n x}$ and $F_{n y}$ are the longitudinal and lateral creep force tangential to the contact surface in $\mathrm{N}$, respectively.

A surface fatigue index (FI), which is a measure of the probability of RCF initiation, is defined as follows $^{11}$

$$
F I=\mu-\frac{k}{p_{o}}
$$

The value of the FI indicates the extent to which the shakedown limit has been exceeded. This shakedown limit is the threshold value for crack generation. The FI is basically the transformation of the threshold curve of the shakedown diagram into a horizontal line. Damage is assumed to occur for $F I>0$ (Figure 5). The FI method gives only the probability of crack generation, which is presented in the form of an index chart, and does not give any information about the propagation of cracks or the number of cracks.

The limitation of the FI prediction model is that the applied shakedown diagram is derived under fullslip conditions. The contact with the gauge corner of a rail is often in full slip, but the contact on the top of the rail is often in partial slip. In the case of partial slip, the maximum principal shear stress is higher than

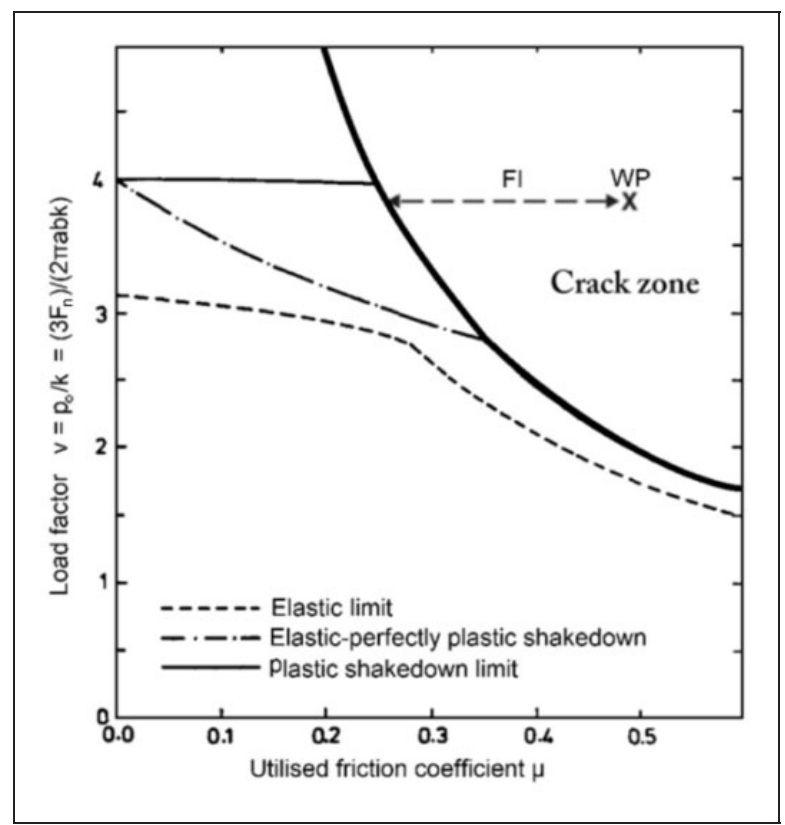

Figure 5. Shakedown map. Surface fatigue is predicted if the working point (WP) (defined by the material yield stress in shear, contact geometry and applied loading) is outside the thick line. Adapted from Dirk et al. ${ }^{12}$ that of full slip, ${ }^{23}$ but in the case of lower friction the difference in shear strength between full and partial slip is small. ${ }^{23}$ Moreover, the FI method does not take the creepage into account, although creepage can be an important variable in determining the fatigue life, nor does the FI method take the possible influence of wear into account, which can also be seen as a limitation.

\section{Results and discussion}

The results shown below are from the leading axle of the first bogie of the wagon. The leading axle often experiences higher forces than the trailing axle and, therefore, the leading axle is more prone to damage. ${ }^{24}$ This makes the leading axle more eligible for the selection for simulations.

\section{Fatigue index chart for the sharpest curve}

The FI chart for the different friction control levels is shown as a function of the position in the curve in Figure 6(a) and (b) for high and low rails, respectively. These figures represent the effect of friction control on the probability of crack generation in the complete curve, including the transition curve, and show how the index changes from the tangent track to the curve track.

The initial $50 \mathrm{~m}$ of the track, starting at $0 \mathrm{~m}$, represent the tangent track. In this zone, the FI values are at the minimum level since the traction forces are small because of the tangent track. After that the transition curve starts, the traction forces between the rail and wheel start to increase and, with this increase in the traction forces, the FI values also increase. The FI values stabilise on reaching the circular curve (at $250 \mathrm{~m}$ ) and remain stable in the whole circular curve $(250-500 \mathrm{~m})$. In the circular curve, if no external force is applied, the motion is also known as quasi-static motion. Due to the quasi-static behaviour in the circular curve, the traction forces remain contant, but small disturbances are noted due to track irregularities. At the end of the circular curve (after $500 \mathrm{~m}$ ), the FI values again go down to the initial FI values generated on the tangent track. One can observe that the tangent part of the track is in the safe zone (no-crack zone), but there is a shift to the crack (positive) zone when the curve radius is decreased, especially for the higher friction values. The topmost curves represent a friction coefficient of 0.5 with a Kalker's reduction factor of $60 \%$. It is also affirmed with the shakedown diagram that a higher friction coefficient leads to a higher probability of crack generation, which is also seen in Figure 6(a) and (b). The friction coefficients with the highest values give the highest FI values, since at higher friction the shear stresses are higher.

The second graph from the top has a lower FI value, as it has a lower friction coefficient value of 
0.4 and a reduction factor of $45 \%$. It can be seen that, by lowering the utilised friction from $\mu=0.5$ to $\mu=0.4$, the probability of crack generation is decreased by $25 \pm 5 \%$ on both the high and the low rail. Here, a friction coefficient of 0.4 with a reduction factor of $45 \%$ is considered as reduced friction, but it is quite often the case that the friction between the rail and wheel is near this value even without friction control. This can happen due to various deposits on the rails from trains and the ambient atmosphere (e.g. moisture).

The next step is to study the friction at $\mu=0.3$ with a reduction factor of $30 \%$, which is the third curve from the top in Figure 6(a) and (b). The probability of crack generation is reduced by $55 \pm 5 \%$ in both the high and the low rail. With this friction coefficient and reduction factor, the FI value has been reduced considerably. However, there will still be cracks on the
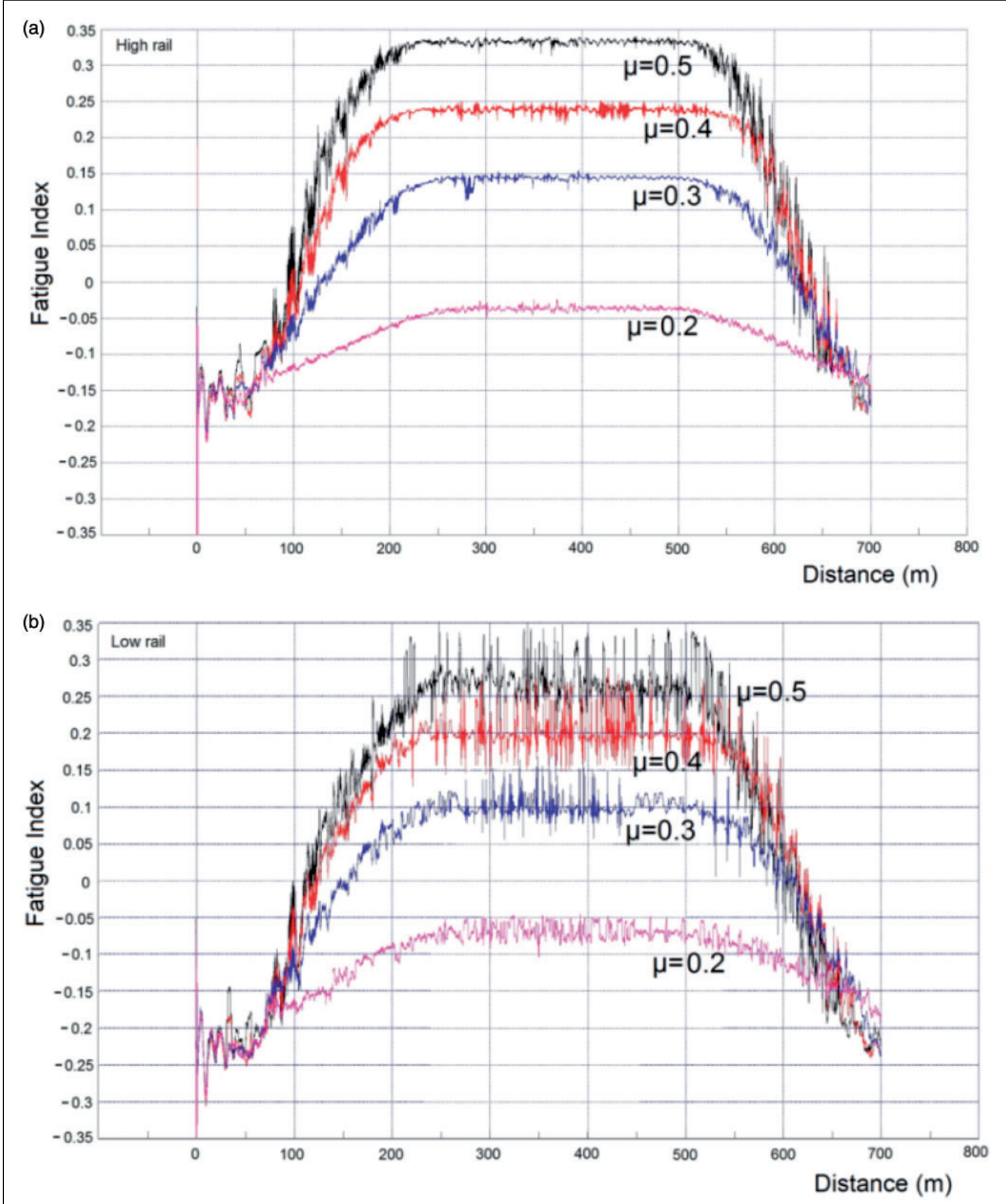

Figure 6. Fatigue index for a $200 \mathrm{~m}$ curve radius at different friction values with respect to the distance in the curve: (a) high rail and (b) low rail. 
rail surface, because the traction force reduction is not sufficient to prevent the generation of cracks. Generally, the friction modifier manufacturers claim that, at this value, crack formation can be avoided, but this has not been observed in the simulations. By reducing the Kalker's reduction factor to a lower value, crack generation can probably be avoided. It should be noted that this study has used old profiles with irregularities, which also increase the risk of crack generation.

The lowest graph represents friction control with $\mu=0.2$ and a reduction factor of $15 \%$. At this level of friction control, the FI value for both the high and the low rail is in the safe zone. According to the railway safety regulations, such a low friction $(\mu=0.2)$ is not recommended on the top of the rail. However, many researchers have shown that the friction coefficient can decrease down to 0.2 , or even lower, with the presence of water or excess friction modifier ${ }^{18}$ and to even lower values in the case of crushed leaves. ${ }^{25}$ Such a low friction can increase the risk of a long braking distance and the possibility of wheel slippage.

On comparing Figures 6(a) and (b), it can be noted that there are large disturbances in the circular curve on the lower rail. These disturbances depend on how well the rail and wheel fits each other and/or presence of track irregularites. By reducing the friction to lower values, the traction force decreases, which in turn also supresses the small disturbances due to worn profiles and track irregularities.

It can also be noted that the FI values for the high rail, for the respective friction control values, are somewhat higher, and the reason for this may be flange hitting. The wheelset wants to travel straight, but the gauge on the high rail presses against the flange of the wheelset, which forces the wheelset to shift (creep) in the lateral direction, causing more creep forces. This flange hitting could be higher on sharp curves because of cant deficiency. Cant deficiency is the difference between the actual field cant and the theoretical cant required at a particular speed to compensate for the centrifugal forces. The cant values used in this study are the actual cant values present in the field, but the field cant values are generally lower than the theoretical value; here a compromise was made due to the occurrence of different traffic and speeds. The cant deficiency can be calculated using the following formula

$$
h_{d}=\frac{2 b_{o}}{g} \cdot \frac{v^{2}}{R}-h_{t}
$$

where $h_{d}$ is the cant deficiency $(\mathrm{m}), 2 b_{o}$ is the track gauge $(\mathrm{m}), v$ is the velocity of train $(\mathrm{m} / \mathrm{s}), R$ is the curve radius (m), $h_{t}$ is the actual cant (m) and $g$ is the gravitational acceleration.

For a $200 \mathrm{~m}$ curve, the cant deficiency is equal to $0.062 \mathrm{~m}$.

\section{Fatigue index value for various axle loads}

It is always desirable to increase the axle load from a load capacity point of view, but in doing so the maintenance cost increases. By controlling the friction there is a possibility that the axle load can be increased without reducing the lifetime of the rails due to surface-initiated cracks. However, the actual economic efficiency and reduction in maintenance costs to be achieved through friction control are still unknown. In order to study the effect of friction control for a range of axle loads, simulations were performed for axle loads of 30 to 40 tonnes. It is not convenient to represent all the curves using different loads and different friction coefficients, and therefore the 95th percentile of all the FI values in the circular curve was used to represent the whole curve. In order to avoid RCF, the FI value should always be lower than zero. If the FI value becomes greater than zero due to irregularities or any other disturbances, a crack will occur. However, selecting the highest FI value as a representative value is not correct because that may result in FI $>0$ for all cases. The maximum value depends on the length of the simulation and the longer a simulation is, the bigger is the risk that the wheel will pass a larger track irregularity. Therefore, the 95th percentile value was chosen instead of the maximum value, because the former is a stable value and independent of the length of the simulation. The 95th percentile means that $95 \%$ of the time, the FI value is at or below the 95th percentile value. Conversely, $5 \%$ of the FI values may exceed this value, but this $5 \%$ is ignored.

Figure 7(a) to (e) shows the 95th percentile for curve radii from $200 \mathrm{~m}$ to $3000 \mathrm{~m}$ and include all the friction coefficients with different Kalker's reduction factors shown in Figure 1 in the 'Friction values' section. Also included in Figure 7(a) to (e) are the individual values for both the high and the low rails. In each successive figure from Figure 7(a) to (e), the axle load is gradually increased by 2.5 tonnes up to 40 tonnes.

In Figure 7(a) to (e), it can be clearly seen that, on increasing the curve radius, the FI values decrease. This is because, when the curve radius is increased and the other parameters are kept constant, the traction forces decrease. From the load point of view, it can be seen that an axle load increment from 30 to 40 tonnes has a negligible effect on the FI value. The FI value depends on the contact pressure, which is the load divided by the contact area. The contact area between the rail and wheel increases with an increasing axle load. Therefore, the FI values are not linearly related to the axle load. This can also be confirmed by calculating the contact pressure according to the Hertz theory at different axle loads. It has been calculated that, on increasing the axle load by $33 \%$ (i.e. from 30 to 40 tonnes), the maximum contact pressure increases only by $9 \%$. If we focus on the 

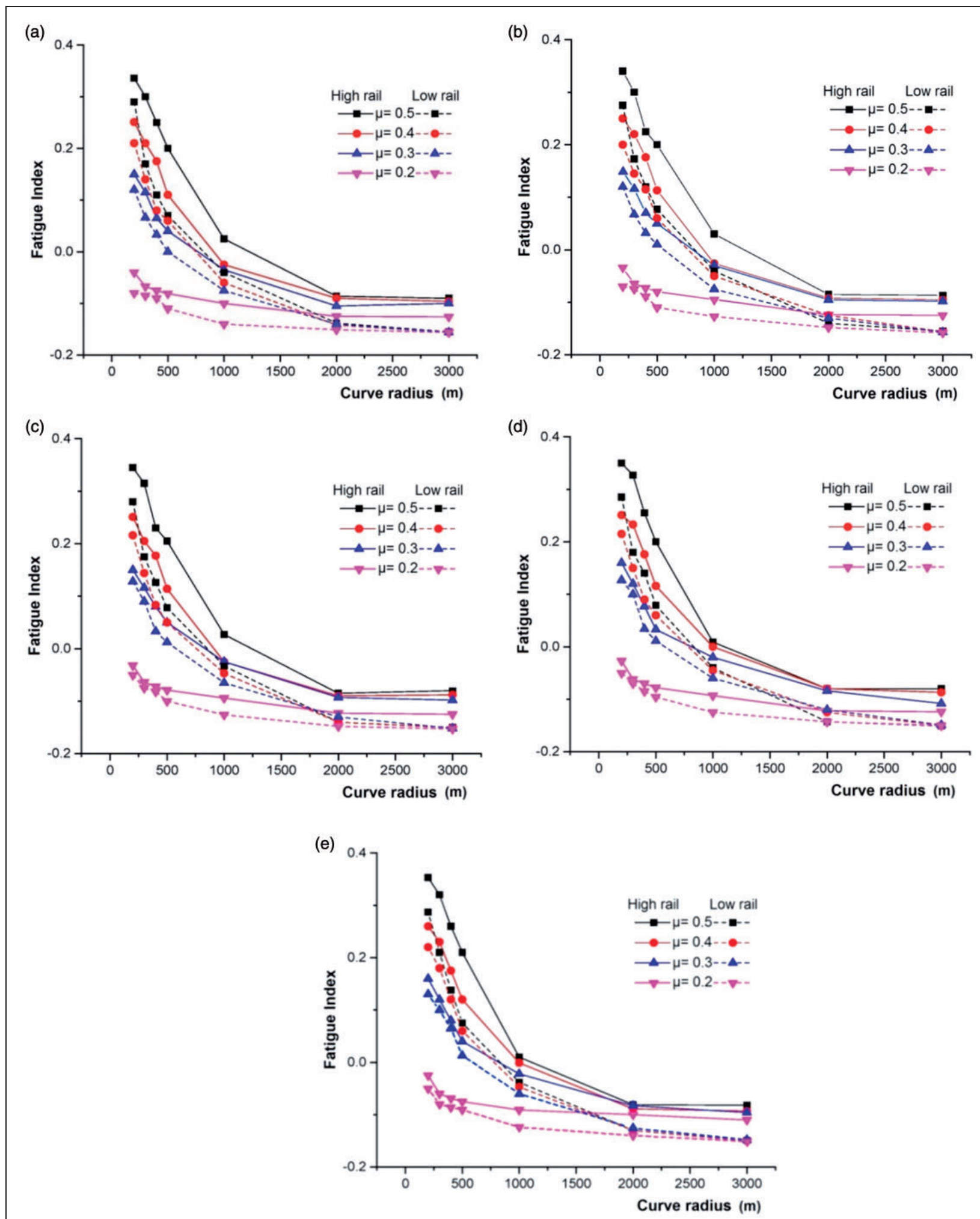

Figure 7. Fatigue index values (95th percentile) of all the curves from $200 \mathrm{~m}$ to $3000 \mathrm{~m}$ at various friction control levels, both for high and low rails: (a) 30 tonne axle load, (b) 32.5 tonne axle load, (c) 35 tonne axle load, (d) 37.5 tonne axle load, and (e) 40 tonne axle load.

FI values, the increments in the FI values due to load increments are quite small and it is quite difficult to see the difference in the various FI charts at different loads in Figure 7(a) to (e). The shape of the rail and wheel profile plays an important role concerning the
FI sensitivity to a load change. If the rail and wheel fit each other well, the area of the contact point easily grows, as in this case, and the FI values are not sensitive to the axle load. However, there could be other cases where the rail and wheel do not fit each other so 
well and the FI values could be more sensitive to the axle load. The effects of profile changes on the FI values are not covered in this paper.

Another aspect which can be observed is that, with an increasing curve radius, the difference in the FI values between the different friction control values decreases. The reason for this is that, with larger curve radii, the traction forces are generally lower and hence the reduction in the FI due to friction control is not significant. The difference in the FI values is small for curve radii $\geqslant 1000 \mathrm{~m}$. For curve radii of $2000 \mathrm{~m}$ and higher, the FI value almost stabilised and all the values are within the safe zone. Therefore, from an RCF point of view, friction control does not play any major role for curves with a radius larger than $1000 \mathrm{~m}$. Friction control probably still plays an important role in reducing corrugation, hunting and squeal noise due to the stick-slip condition, but these areas of research are not within the scope of this study.

\section{Conclusions}

Based on the use of the FI method in this study to predict the effect of friction control on top-of-rail cracks, the following conclusions can be drawn.

1. By controlling the utilised friction, reducing the friction coefficient to 0.4 and using a reduction factor of $45 \%$, for curve radii smaller than $1000 \mathrm{~m}$, the probability of crack formation is decreased by at least $25 \%$.

2. In the case of sharp curves $(R<500 \mathrm{~m})$, by using a friction coefficient of 0.30 and a Kalker's reduction of $30 \%$, the probability of crack generation is reduced by at least $50 \%$, but there is still a probability of crack generation. Curves with a radius larger than $500 \mathrm{~m}$ are mostly in the safe zone for this friction control level.

3. The friction coefficient should be at most 0.2 to avoid crack generation in curves smaller than $500 \mathrm{~m}$ (and even in curves with a larger radius in some cases involving the high rail). However, this friction control level will probably result in too long a braking distance.

4. For higher curve radii $(>1000 \mathrm{~m})$, friction control does not have any major effect on crack formation but may still result in other benefits, such as a reduction in the fuel/power consumption, corrugation and hunting.

5. On increasing the axle load, no major changes in the FI value are observed. The FI value depends on the pressure and, on increasing the axle load, the contact pressure does not increase at the same rate. This implies that the curve radius has much more impact on the crack generation than the axle load. However, an increased load may have other negative effects on the maintenance cost.
6. It is possible that, on reducing the Kalker's reduction factor at $\mu=0.3$, the working point may shift to the no-crack zone. This implies that the simulation results are highly dependent on the Kalker's reduction factor.

\section{Acknowledgements}

The authors would like to acknowledge gratefully the support rendered by Thomas Nordmark, Matthias Asplund and Matti Rantatalo at the Division of Operation and Maintenance of Luleå University of Technology for their assistance and expertise.

\section{Declaration of Conflicting Interests}

The author(s) declared no potential conflicts of interest with respect to the research, authorship, and/or publication of this article.

\section{Funding}

The author(s) disclosed receipt of the following financial support for the research, authorship, and/or publication of this article: This research was supported and funded by Luleå Railway Research Centre (JVTC) and Trafikverket (the infrastructure manager in Sweden).

\section{References}

1. European Commission. White paper: Roadmap to a Single European Transport Area-Towards a competitive and resource efficient transport system. Epubl ahead of print 2011. DOI: 10.2832/30955.

2. Stenstrom C, Parida A, Galar D, et al. Link and effect model for performance improvement of railway infrastructure. Proc IMechE, Part F: J Rail Rapid Transit 2013; 227: 392-402.

3. Andersson E, Berg M and Stichel S. Rail vehicle dynamics course book. Stockholm: KTH, 2014.

4. Bower AF and Johnson KL. Plastic flow and shakedown of the rail surface in repeated wheel-rail contact. Wear 1991; 144: 1-18.

5. Eadie DT, Vidler B, Hooper NE, et al. Top of rail friction control: Lateral force and rail wear reduction in a freight application. In: Proceedings of international heavy haul association conference, Dallas, TX, USA, 5-9 May 2003, pp.573-581, 7-35.

6. Eadie DT, Oldknow K, Maglalang L, et al. Implementation of wayside top of rail friction control on north american heavy haul freight railways. In: Proceedings of the seventh world congress on railway research, Montreal, Canada, 2006, pp.2-11.

7. Lu X, Makowsky TW, Eadie DT, et al. Friction management on a Chinese heavy haul coal line. Proc IMechE, Part F: J Rail Rapid Transit 2012; 226: 630-640.

8. Spiryagin M, Sajjad M, Nielsen D, et al. Research methodology for evaluation of top of rail friction management in Australian heavy haul networks. Proc IMechE, Part F: J Rail Rapid Transit 2014; 228: 631-641.

9. Hardwick $\mathrm{C}$ and Lewis R. The effects of alternative top of rail friction materials on pre existing rolling contact fatigue. In: Proceedings of the second international 
conference on railway technology: Research, development and maintenance. Scotland: Civil-Comp Press, 2014.

10. Eadie DT, Elvidge D, Oldknow K, et al. The effects of top of rail friction modifier on wear and rolling contact fatigue: Full-scale rail-wheel test rig evaluation, analysis and modelling. Wear 2008; 265: 1222-1230.

11. Ekberg A, Kabo E and Andersson H. An engineering model for prediction of rolling contact fatigue of railway wheels. Fatigue Fract Eng Mater Struct 2002; 25: 899-909.

12. Dirks B and Enblom R. Prediction model for wheel profile wear and rolling contact fatigue. Wear 2011; 271: 210-217.

13. Olofsson $U$ and Telliskivi T. Wear, plastic deformation and friction of two rail steels - A full-scale test and a laboratory study. Wear 2003; 254: 80-93.

14. VanderMarel J, Eadie DT, Oldknow KD, et al. A predictive model of energy savings from top of rail friction control. Wear 2013; 314: 155-161.

15. Gensyshttp://www.gensys.se (accessed 1 April 2016).

16. Kalker JJ. A fast algorithm for the simplified theory of rolling-contact. Veh Syst Dyn 1982; 11: 1-13.

17. Lu X, Cotter J and Eadie DT. Laboratory study of the tribological properties of friction modifier thin films for friction control at the wheel/rail interface. Wear 2005; 259: $1262-1269$.
18. Lundberg J, Rantatalo M, Wanhainen $\mathrm{C}$, et al. Measurements of friction coefficients between rails lubricated with a friction modifier and the wheels of an IORE locomotive during real working conditions. Wear 2014; 324-325: 109-117.

19. Johnson KL. Contact mechanics. Cambridge: Cambridge Press, 2003

20. Suda Y, Iwasa T, Komine H, et al. Development of onboard friction control. Wear 2005; 258: 1109-1114.

21. Nia SH. An investigation of the iron-ore wheel damages using vehicle dynamics simulation. Sweden: KTH, 2014.

22. Voestelpine. Heat treated high performance rail 350 LHT, https://www.voestalpine.com/schienen/static/ sites/c011/downloads/downloads/Guetenfolder 350LHT_HSHx_en.pdf (accessed 11 April 2016).

23. Dirks B. Simulation and measurement of wheel on rail fatigue and wear. Sweden: KTH, 2015.

24. Oldknow K, Eadie DT and Stock R. The influence of precipitation and friction control agents on forces at the wheel/rail interface in heavy haul railways. Proc IMechE, Part F: J Rail Rapid Transit 2012; 227: 86-93.

25. Gallardo-Hernandez EA and Lewis R. Twin disc assessment of wheel/rail adhesion. Wear 2008; 265: 1309-1316. 